\title{
Effect of Garlic and Eucalyptus oils in comparison to Organophosphatinsecticides against some Piercing-Sucking Faba bean insect Pests and natural enemies populations
}

\author{
Mousa K. M.; I. A. Khodeir; T.N. El-Dakhakhni and A. E. Youssef \\ Economic Entomology Department, Faculty of Agriculture, kafrelsheikh University, \\ kafr El-Sheikh 33516, Egypt.
}

\begin{abstract}
The efficacy of garlic Allium sativum oil, and eucalyptus Eucalyptus globulus oil and their combinations with two organophosphorus pesticides, Dimethoate $30 \%$ and Pestban 48\% were evaluated for the control of some Piercing-Sucking insect pests associated with Faba bean Vicia faba in open field, during season 2011/2012. All of the four composites diluted to 3\% before applying for four times in each spray. Samples were taken at the first, fifth, seventh and tenth days after application to determine the reduction in numbers. The results showed that, garlic oil was the best efficient in reducing the population of leafhoppers and planthoppers by a mean reduction percentage of $68.09 \%$, followed by the two chemical insecticides Dimethoate $67.90 \%$ and Pestban $64.02 \%$, and Eucalyptus oil was the least in this category as $43.27 \%$. However in controlling aphids, also garlic surpasses again by a mean overall reduction $90.96 \%$, followed by Pestban $89.44 \%$, while eucalyptus oil came in the third rank as $80.66 \%$ before the dimethoate which achieved the least rank in controlling aphids as $76.14 \%$. Furthermore experiment was conducted also to evaluate the side effects of such composites on the population fluctuations of two insect predators rife in Fababean fields, true spiders and minute pirate bug (Orius sp.). Data showed that, in compared with control, the use of natural oils preserved partly the coexist of natural enemies than the use of chemical compounds in Faba bean fields.
\end{abstract}

Keywords: Faba bean (Vicia faba), plant oils, Allium sativum, Eucalyptus globulus, Organophosphorus pesticides, Population reduction and Natural enemies.

\section{INTRODUCTION}

Faba bean (Broad bean) (Vicia faba L.) is an important feeding crop grown in winter season. It is a hardy grain legume originally domesticated in the Hindustani region of central Asia, but now cultivated from tropic to sub-arctic climates (Uessly et al., 2004). The Mediterranean regions represent almost $25 \%$ of the total cultivated area (Saxena, 1991), and north Africa consider as one of the topproducing region of the broad bean (Aouar-sadli et al., 2008), and Egypt cultivated area of faba bean reached 55200 hectares with total production 174631 tonnes in 2011 season (FAO, 2011).The pest management in agriculture is facing challenge in development of suitable agents to manage the insect pests while ensuring the economic and ecological sustainability. However, concern has arisen about the negative impact that such chemicals have on human health and environment besides reducing the number of species and density of natural enemies, developing resistance and increasing production costs. For example, Dimethoate is one of the world's largest organophosphorous insecticides used to control a wide range of Acari, Aphididae, Aleyrodidae, Coccidae, Coleoptera, Collembola, Diptera, Lepidoptera (FAO, 2005), it showed a clinical signs in rats 
prior to death included gait alterations, constricted pupils, salivation, tremors, absent forelimb/hindlimb grasp, laboured and shallow respiration (Anonymous, 2010). Also, Pestban has a moderately hazardous (Pereira et al., 2007), when applied on fish it appears an exhibited loss of equilibrium, nervous manifestation with erected pectoral fins. In addition, increase the mucus secretion and the fish exhibited a respiratory distress. The postmortem alterations revealed congestion of the internal organs (El-Ashram and Mohammed, 2011).

The growing demand for natural products has intensified in the past decades as they are extensively used as biologically active compounds and, are being considered an important alternative strategy for the sustainable insect pest management in agriculture (Rattan, 2010). Essential oils are volatile, natural, complex compounds characterized by a strong odor and are formed by plants as secondary metabolites ( Sharaby et al., 2012 ). In nature, essential oils seems to be important agents of interspecific communication as they are favour pollination by attracting insects, they also play an important role in protection of the plants as antibacterial, antiviral, antifungal, insecticides and also against herbivorous by reducing their appetite for such plants (Bakkali et al, 2008). Subsequently, they have involved in many industrial applications, particularly in perfumery, cosmetics, detergents, pharmacology, fine chemistry as well as aromatics for the food industry and recently in insect pest management (Regnault-Roger, 1997). Eucalyptus is one of the most cultivated genera in the world, including more than 700 species belonging to family Myrtaceae (Maciel et al., 2010). Various biological properties have already been attributed to the genus Eucalyptus, among them larvicidal activity on culicids (Cheng et al., 2009), insecticidal activity against beetles (Brito et al., 2006), repellent action against
Phlebotomus papatasi (YaghoobiErshadi et al., 2006) and acaricidal activity against Tetranychus urticae (Afify et al., 2012). However, Garlic extract has insecticidal properties. (Ho et al., 1996), and shown considerable toxicity to a number of pest species, across all life stages; susceptible orders include the Coleoptera, Lepidoptera, Homoptera and Diptera (Prowse et al., 2006 and Kazem and El-Shereif, 2010). However, they are not as effective and fast acting as synthetic chemicals can be, but they are safer for the environment and consumers. Therefore, the purpose of this paper is to evaluate the impact of these two natural plant oils and some synthetic insecticides in controlling piercing-sucking insects in open field. Furthermore, side effects of those insecticides and biocides on two of nontarget insect predators associated with faba bean plants were estimated.

\section{MATERIALS AND METHOD}

\section{Experiment design:}

Located at the teaching and experimental farm of faculty of agriculture kafrelsheikh University, the experiment plot was cleared, stumped and a total land area of $16 \mathrm{~m}$. width $\times$ $43.5 \mathrm{~m}$. long marked out. Suitable seedbeds were prepared and Faba bean seeds (Giza 3 cultivar) planted soon after seedbed preparation. Four experimental treatments in a completely randomize blocks design were conducted and each treatment was replicated three times in addition to three replicates which sprayed by water as a control. The replicate consisted of four lines area for each $5 \mathrm{~m}$. width $\times 8.3 \mathrm{~m}$. long, and each block surrounded by $50 \mathrm{~cm}$ separated blank area.

\section{Sampling Procedure:}

Samples of leafhoppers, planthoppers and aphid presented in Faba bean field were taken before treatment four times 27,24 , ten and one day before treatment, once the day of application samples were taken also for four times as 
one, five, seven and ten days after application to determine the reduction in arthropods numbers. Insect pest populations were determined by a fine sweep net, fifty double strokes were diagonally conducted then a direct counting of arthropods numbers found after anesthetization was done.

\section{Chemicals and plant extractions used:}

Two absolute essential plant oils Garlic (Allium sativum L.) and Eucalyptus (Eucalyptus globulus Labill.) and two organophosphorus insecticides, Dimethoate $30 \%$ EC, (O,O-dimethyl Smethylcarbamoylmethyl, phosphorodithioate) phosphorodithioate) and Pestban 48\% EC (O,O-Diethyl o-3,5,6,trichloro-2-pyridyl phosphorodithioate) were used. All of the four compounds subsequently diluted to $3 \%$ before applying, and the Knapsack sprayer (20 L volume) was used to spray the tested compounds.

\section{Statistical analysis:}

The obtained data were subjected to the analysis of variance test (ANOVA) with mean separation at 5\% level of significance according to the method of (Snedecor and Cocharn, 1967). Percentage reduction of the insect populations were calculated according to the equation of (Henderson and Tilton,1955) formula as follows:

Population reduction $\%=100 \times\left[1-\frac{T a \times C g}{T E \times C a}\right]$

Where: $\mathrm{Ta}=$ Population in treated plots after treatment, $\mathrm{Tb}=$ Population in treated plots before treatment, $\mathrm{Ca}=$
Population in control after treatment, and $\mathrm{Cb}=$ Population in control before treatment. And to calculate the reduction according this formula we determined $(\mathrm{Tb})$ here as the immediately preceding day for treatment.

\section{RESULTS AND DISCUSSION}

Two targeted groups of piercingsucking insect pests were identified to study the impact of such composites, the first group is leafhoppers and planthoppers and the second one is aphids. It was noticeable that Empoasca sp., Balclutha sp. Oliarus frontalis Melichar and Exitianus taeniaticeps (Kirschbaum) were the most abundant among this group. Whereas, only the two aphids species Macrosiphum sp. and Aphis craccivora Koch. Were conducted in the second group.

Data on mean percent values of Leafhoppers and planthoppers $(\mathrm{H})$ and Aphids (A) populations as affected by the different treatments of the four spraying compounds as tabulated in Table 1. Data showed that garlic oil was the best efficient in reducing the populations of leafhoppers and planthoppers by a mean percentage of $68.09 \%$, and also it was the most effective in reducing aphid populations as $90.98 \%$. Garlic oil showed a high reduction level against hoppers in the fifth day after application reducing $87.60 \%$ of its numbers, this ratio decreased in the seventh day as $72.60 \%$ to reach the minimum level due to the fourth treatment as $40.50 \%$.

Table 1: Effect of multiple treatments of two insecticides and two natural plant oils and it's reduction (\%) against two Piercing-Sucking insectpests in Fababean open field.

\begin{tabular}{|c|c|c|c|c|c|c|c|c|c|c|c|c|c|c|c|c|c|c|c|c|c|c|}
\hline \multirow{3}{*}{ Treathent } & \multirow{2}{*}{\multicolumn{2}{|c|}{$\begin{array}{l}\text { No.hefore } \\
\text { treatment }\end{array}$}} & \multicolumn{10}{|c|}{ No. after treatment } & \multicolumn{10}{|c|}{$\%$ Fopulations retuction } \\
\hline & & & \multicolumn{2}{|c|}{$1 \mathrm{dxy}$} & \multicolumn{2}{|c|}{5 dxys } & \multicolumn{2}{|c|}{7 dxys } & \multicolumn{2}{|c|}{10 dxys } & \multicolumn{2}{|c|}{ Total } & \multicolumn{2}{|c|}{ 1dxy } & \multicolumn{2}{|c|}{5 dxys } & \multicolumn{2}{|c|}{7 dxys } & \multicolumn{2}{|c|}{10 dxys } & \multicolumn{2}{|c|}{ Average } \\
\hline & H. & $\mathbf{A}$ & H. & $\mathbf{A}$. & H. & $\mathbf{A}$. & \begin{tabular}{|l}
$\mathbf{H}$ \\
\end{tabular} & A. & H. & A. & H. & $\mathbf{A}$. & H. & $\mathbf{A}$. & H. & $\mathbf{A}$. & H. & A. & H. & $\mathbf{A}$. & H. & $\mathbf{A}$. \\
\hline Garic oll & 192 & 526 & 4730 & 83 & 18 & 2 & 37 & 0 & 87 & 0 & 1863 & $1030^{\circ}$ & 7168 & 71.78 & 8760 & 92.14 & 7260 & 100 & 4050 & 100 & $6809^{-}$ & 9098 \\
\hline $\begin{array}{l}\text { Bucalyptus } \\
\text { oil }\end{array}$ & 193 & 127 & 8830 & 323 & 666 & 45 & 64 & 8 & 27 & 7 & 2459 & $5180^{\circ}$ & 47.40 & $54 s 1$ & 54.46 & 9267 & 5289 & 8934 & 1835 & 86.14 & $4327^{\circ}$ & 80.66 \\
\hline pestian & 234 & 1026 & 10260 & 53 & 69 & 3 & 40 & 0 & 54 & 11 & 2656 & 1930 & 4959 & 90.76 & 6109 & 9396 & 75.71 & 100 & 69.72 & 7305 & $64.02^{-}$ & 89.44 \\
\hline fimefhoste & 2135 & 92 & 78 & 18 & 36 & 5 & 53 & 0 & 47 & 18 & 214 & $41^{6}$ & 5800 & 6500 & 77.75 & 88.76 & 64.73 & 100 & 71.12 & 5082 & $6790^{\circ}$ & 76.14 \\
\hline Control & 223 & 93 & 194 & 52 & 169 & 45 & 157 & ss & 170 & 37 & $690^{\circ}$ & $189^{\prime}$ & 000 & 0.00 & 0.00 & 000 & 000 & 000 & 000 & 0.00 & 0.00 & 000 \\
\hline
\end{tabular}

Means followed by the same letter are not significantly different, $\mathrm{P}>0.05$, Tukey-Kramer HSD. 
While the same composite reducing $71.78 \%$ of aphid population after one day of treatment, then a drastic drop has been occurred in aphid population density to reach $100 \%$ in both seventh and tenth days from application.

On the other hand, Eucalyptus oil was the least harmful against hoppers populations resulting in $43.27 \%$ overall reduction and the fifth day after treatment was the most effective as $54.46 \%$ and the last day of treatment was the least in that trend as $18.35 \%$. Whereas, eucalyptus oil induced an overall reduction $80.66 \%$ against aphid populations surpassing the chemical composite dimethoate which showed $76.14 \%$. The fifth day after treatment showed the top of its reaction against aphids as $92.67 \%$ decreased gradually to $89.34 \%$ and $86.14 \%$ in the seventh and last sampling day respectively. (Regnault-Roger, 1997) revealed that the toxic effect of essential oils was not only suitable for granary insects but also for flying insects, data showed that the effect of both the garlic and eucalyptus oils on aphid which is a sedentary insect, was more than that in leafhoppers and planthoppers, and that may be due to its active mobility which assist to avoid the impact of treated composite. Statistical analysis revealed that the differences among insect numbers were highly significant, where control recorded the highest number of insects, garlic oil had the big impact on both of leafhoppers and planthoppers and aphid populations. Moreover, a highly significant differences were noticed among the treatments in leafhoppers and planthoppers and aphid population reduction. The maximum reduction obtained in hoppers distributed between garlic oil, pestban and dimethoate, while eucalyptus came in the second rank. Whereas, no variations were recorded in aphid populations reduction values among various treatments.

The present work essentially designed to evaluate the efficiency of the natural oils as insecticid treatments for controlling some piercing-sucking insect pests, at the other portion it aims to evaluate the side effect of such compounds on two associated predators, true spiders and minute pirate bug (Orius spp.). Data illustrated in Fig. 1 showed the population fluctuation of true spiders influenced by different sprays among the diverse compounds, data indicated that numbers of such predators fluctuated in a natural image before application tell the first day of treatment, then, a drastic drop occurred as a result of spraying the two organophosphate compounds, tell the end of the experiment.

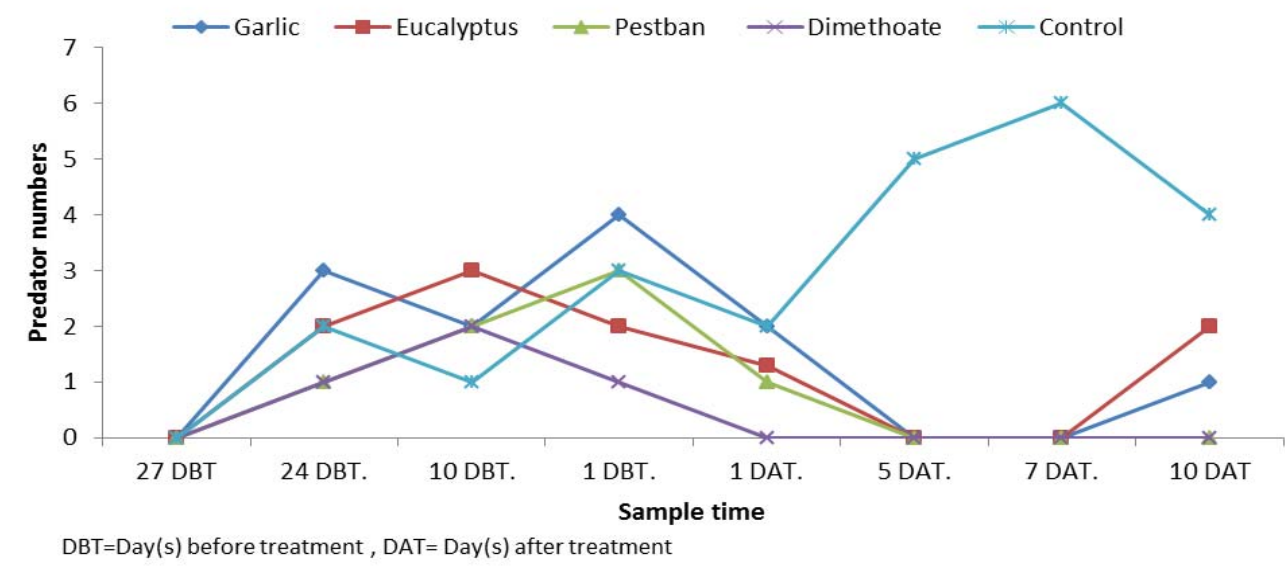

Fig. 1: True spiders population fluctuations influenced by multiple composites during different experiment days. 
Compared with the control, a considerable reduction was observed in the period between the second sample (five days after) and the third one (seven days after) caused by the two natural oils, then it began to restore its numbers concurrently with the last treatment. While, the population fluctuation of minute pirate bug showed in Fig. 2 indicated that Orius began to appear in scant numbers at the beginning of the experiment, then it increased gradually to recording a peak which synchronized with the tenth day before treatment, then it decreased slightly at one day before application. Just the day of spraying and when collecting specimens in the next day a sudden drop happened in plots treated with the two organophosphorus pesticides in the period between the first and the seventh day after treatment, it began to appear again with the last day of experiment in plots treated with dimethoate. However, in compared with the controlled plots, both of garlic and eucalyptus oils had a minor impact, appeared in a trivial decrease in predator numbers.

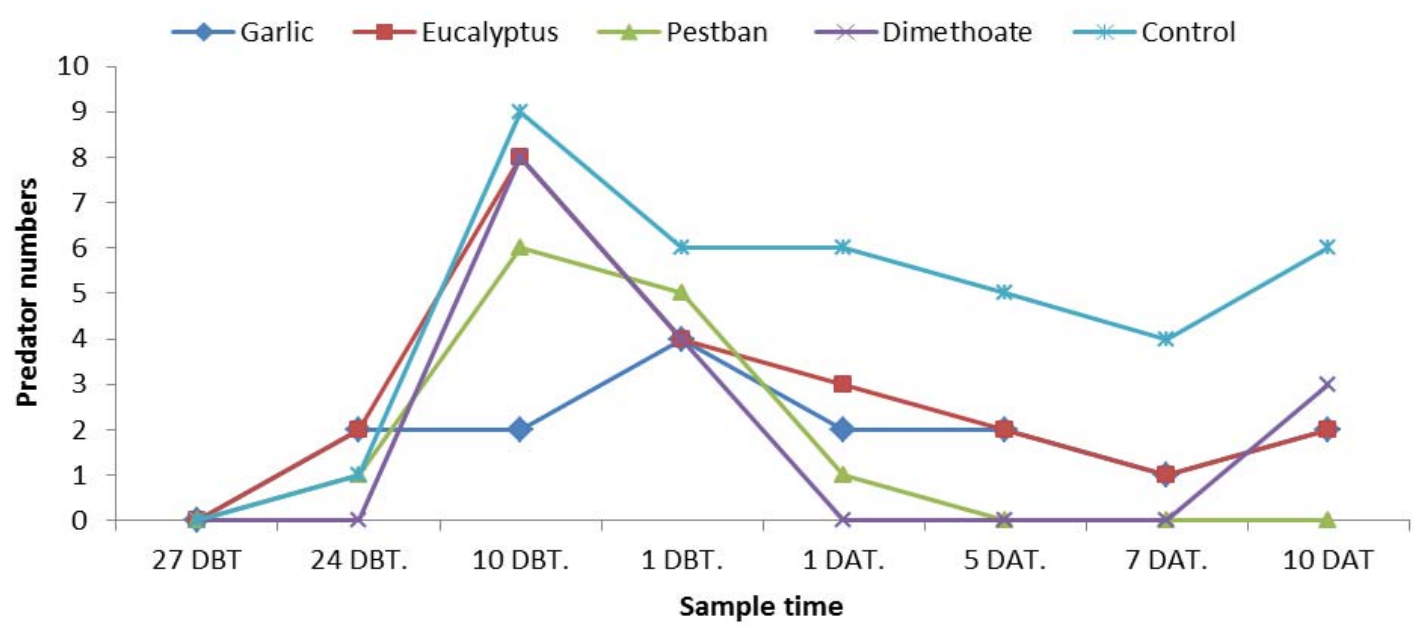

DBT=Day(s) before treatment , DAT= Day(s) after treatment

Fig. 2: minute pirate bug population fluctuations influenced by multiple composites during different experiment days.

From results obtained, it is obvious that the use of chemical insecticides gave better and fast protection, but at a convergent proportion with garlic oil in controlling both of hoppers and aphids. Nevertheless, garlic and eucalyptus oils superiority the organophosphorus insecticides in a partly maintaining the natural enemies

\section{ACKNOWLEDGMENTS}

Authors would like to thank Mrs. Rowfida bassiony, assistant researcher plant protection institute, agricultural research center, for her efforts helping in specimens management and arrangement. Great thanks extended to Dr. Mohammed kamara, lecturer of agronomy science faculty of agriculture kafrelsheikh university, for helping in statistical analysis needed in this paper

\section{REFERENCES}

Afify, A.M.; Fatma S. Ali and A.F. Turky (2012). Control of Tetranychus urticae Koch by extracts of three essential oils of chamomile, marjoram and Eucalyptus. Asian Pacific J. of Tropical Biomedicine 24-30.

Al-Ashram, A.M. and M. A. Mohammed (2011). Evaluation of activated charcoal as a protective agent against toxicity of cadmium or 
Pestban in African catfish (Clarias gariepinus) .J. of the arabian aquaculture society. 6(1):86-100.

Anonymous (2010). Human health risk assessment of dimethoate. Australian pesticides and veterinary medicines authority chemical review program.

Aouar-sadli, M.; K. Louadi and S. Doumandji (2008). Pollination of the broad bean (Vicia faba L. var. major) (Fabaceae) by wild bees and honey bees (Hymenoptera: Apoidea) and its impact on the seed production in the Tizi-Ouzou area (Algeria). African J. of Agric. Res., 3 (4): 266-272.

Bakkali, R.; S. Averbeck; D. Averbeck and M. Idaomar (2008). Biological effects of essential oils. - Areview. Food and Chemical Toxicology, 46: 446-475.

Brito, J.P; J.E. Oliveira and S.A. Bortoli (2006). Toxicidade de oleos essenciais de Eucalyptus spp. sobre Callosobruchus maculatus (Fabr., 1775) (Coleoptera: Bruchidae). Rev. Biol. Sci. da Terra. 6:96-103.

Cheng, S. S.; C.G. Huang; Y. J. Chen; J. J. Yu; W. J. Chen and S.T Chang (2009). Chemical compositions and larvicidal activities of leaf essential oils from two eucalyptus species. Bioresour. Technol., 100: 452-456.

FAO. (2005). Food and agriculture organization of the United Nations. (FAO).http://www.fao.org/ag/AGP/ AGPP/Pesticid/Specs/docs/Pdf/new /dimethoa.pdf

FAO. (2011). Food and agriculture organization of the United Nations. FAOSTAT. http://faostat.fao.org/.

Henderson, C. F. and E. W. Tilton (1955). Tests with acaricides against the brown wheat mite. J. Econ. Entomol., 48: 157 - 161.

Ho, S. H.; L. Koh L; Y. Ma; Y. Huang and K.Y. Sim K. (1996). The oil of garlic, Allium sativum L. (Amaryllidaceae), as a potential grain protectant against Tribolium castaneum (Herbst) and Sitophilus zeamais Motsch. Postharvest Biology and Technology, 9:41-48.

Kazem, M.G. and A.E. El-Shereif (2010). Toxic Effect of Capsicum and Garlic Xylene Extracts in Toxicity of Boiled Linseed Oil Formulations against Some Piercing Sucking Cotton Pests. American-Eurasian J. Agric. \& Environ. Sci., 8 (4): 390-396.

Maciel, M.V.; S.M. Morais; C.M. Bevilaqua; R.A. Silva; R.S. Barros; R.N. Sousa; L.C. Sousa; E.S. Brito and M.A. Souza-Neto (2010). Chemical composition of Eucalyptus spp. essential oils and their insecticidal effects on Lutzomyia longipalpis. Veterinary Parasitology, 167:1-7.

Pereira, L.M.; K. Boysielal and A. SiungChang (2007). Pesticide regulation, utilization, and retailers selling practices in Trinidad and Tobago, West Indies: current situation and needed changes. J. Public Health, 22(2):83-90.

Prowse, G.M.; T.S. Galloway and A. Foggo (2006). Insecticidal activity of garlic juice in two dipteran pests. Agric. and Forest Entomol., 8:1-6.

Rattan, R.S. (2010). Mechanism of action of insecticidal secondary metabolites of plant origin. Crop Protection, 29:913-920.

Regnault-Roger, C. (1997). The potential of botanical essential oils for insect pest control. Integrated Pest Management Reviews 2:25-34 .

Saxena MC (1991). Status and scope for production of faba bean in the Mediterranean countries. Options Méditerranéennes. Série Séminaires, 10: 15-20.

Sharaby, A.; S.A. Montasser; Y. A. Mahmoud and S. A. Ibrahim (2012). Natural Plant Essential Oils for Controlling the Grasshopper (Heteracris littoralis) and their Pathological Effects on the 
Alimentary Canal. Ecologia Yaghoobi-Ershadi, M.R.; A.A. Akhavan; balkanica, 4(1):39-52.

E. Jahanifard; H. Vantandoost; G. H. Amin; L. Moosavi; A.R. Snedecor, G.W. and G. Cochran (1967). Statically methods $6^{\text {th }}$ ed, lowa state Ramazani; H. Abdoli and M.H. Univ., Press lowa, USA, 560 pp.

Uessly, G.S.; M.G. Entz; R.B Eiriger and B.T. Cully (2004). Insects associated with faba bean, vicia faba (fabales: fabaceae), in southern Florida. Florida Arandian (2006). Repellency effect of Myrtle essential oil and DEET against Phlebotomus papatasi, under laboratory conditions. Iran. J. Publ. Health, 35:7-13.

Entomologist, 87(2):204-211.

\section{ARABIC SUMMARY}

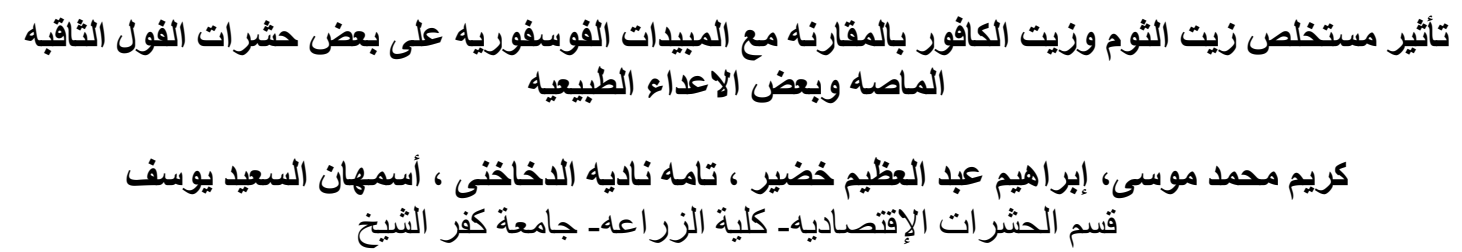

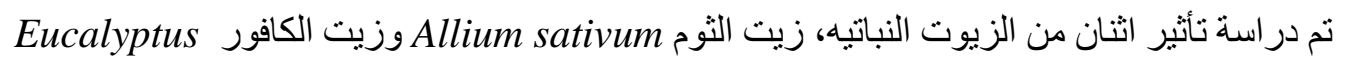

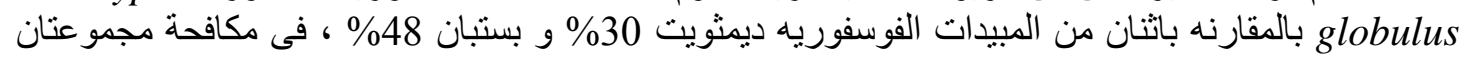

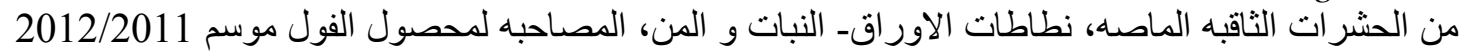

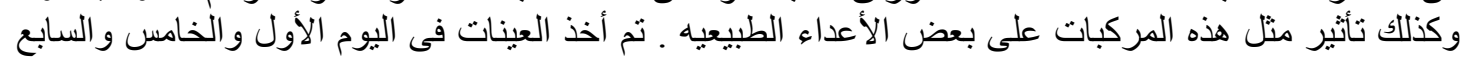

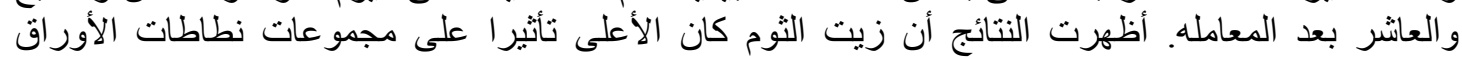

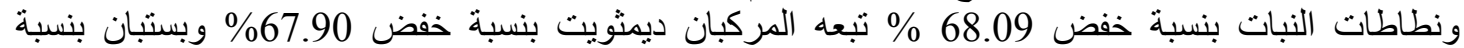

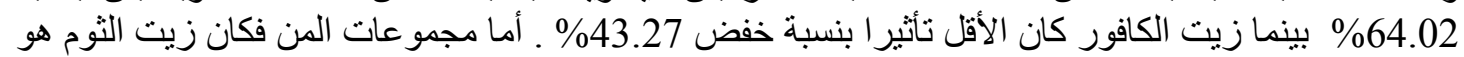

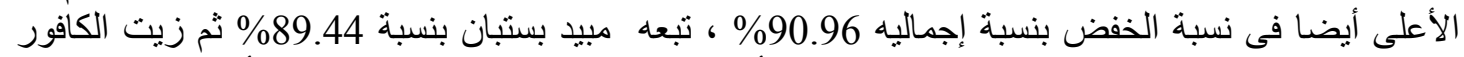

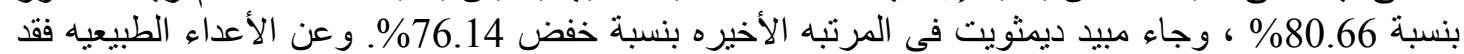

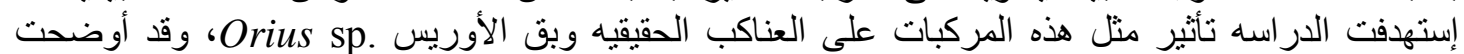

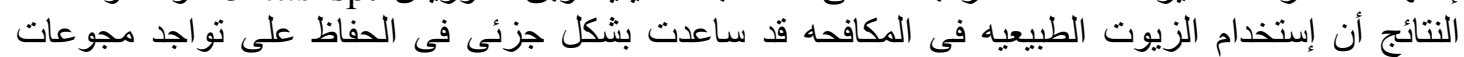
الأعداء الطبيعيه داخل حقول الفول بالمقارنه بتأثير المبيدات الحشريها 